\title{
Further Dopaminergic Supersensitivity to Dopamine Agonists by Subchronic Administration of Haloperidol in Rats Treated with Colchicine
}

\author{
Katsuo KAMATA, Shigeru OKUYAMA*, Sanae HASHIMOTO*, \\ Hironaka AIHARA* and Yutaka KASUYA \\ Department of Pharmacology. School of Pharmacy. Hoshi University, Tokyo 142, Japan \\ * Research Center. Taisho Pharmaceuticals. Saitama 330, Japan \\ Accepted August 11, 1986
}

\begin{abstract}
Effects of subchronic administration of haloperidol on the circling behavior induced by dopamine agonists were examined in rats treated with colchicine. Methamphetamine and apomorphine produced contralateral or ipsilateral rotation in colchicine-treated rats, and these circling behaviors were significantly increased by subchronic treatment with haloperidol. These results suggest that development of supersensitivity following colchicine and subchronic haloperidol may occur through different mechanisms.
\end{abstract}

When colchicine, a drug which has been known to suppress axoplasmic transport, is directly applied to a nerve, axoplasmic transport is blocked, causing a denervationlike supersensitivity of skeletal $(1-4)$ and smooth muscle (5-7). Recently, we have reported that denervation-like supersensitivity can be caused by the block of axoplasmic transport in the central nervous system (8). It has been reported by us that methamphetamine, an indirectly acting dopamine agonist, produces contralateral circling behavior and apomorphine produces an ipsilateral followed by a contralateral circling behavior in rats injected with colchicine into the substantia nigra pars compacta (SNC), and we reported that colchicine might produce changes in postsynaptic dopamine receptors by interrupting the fast axonal transport of trophic factor(s) as it is known to do in the peripheral adrenergic nerve fibers (9-11).

On the other hand, chronic administration of neuroleptics has been shown to produce a supersensitivity to dopamine agonists after these drugs are withdrawn (12-14). In these animals, dopamine receptor binding in the neostriatum is increased (15), and there is a corresponding increase in the behavioral response to dopamine agonists (16-18) Furthermore, it has recently reported that the up-regulation of dopamine receptors in rat nucleus accumbens or caudate nucleus after denervation and receptor blockade is additive $(19,20)$.

In the present study, we investigated the effect of subchronic haloperidol on the denervation-like postsynaptic supersensitivity to dopamine agonists induced by microinjection of colchicine into the SNC by using the circling behavioral model which has been established by Ungerstedt $(21,22)$. The purpose of the present study was to determine whether development of supersensitivity following the block of axoplasmic transport and that due to receptor blockade could arise from independent mechanisms.

All experiments were carried out on male rats of the Wistar strain weighing 200-300 g. The surgical procedure for lesioning of the SNC has been described previously (8, 2325). Briefly, the rats were anesthetized with pentobarbital sodium ( $40 \mathrm{mg} / \mathrm{kg}$, i.p.), placed in a stereotaxic apparatus and subsequently subjected to the surgical operation as follows: Following exposure of the skull, a burr hole was drilled over the left SNC (approximately $2.8 \mathrm{~mm}$ anterior to lambda, $2.0 \mathrm{~mm}$ lateral to 
the midline) according to the stereotaxic atlas of König and Klippel (26). A stainlesssteel cannula attached to a microsyringe containing $20 / \mathrm{g} / \mathrm{m} /$ colchicine in sterile saline was lowered $7.3 \mathrm{~mm}$ ventral to the dura. The cannula was kept in position for $5 \mathrm{~min}$ before a $1 \mu \mid$ volume of the solution of colchicine was injected at a rate of 0.5 all min. The cannula remained in place for an additional $5 \mathrm{~min}$ and then was slowly withdrawn from the brain. The wound area was closed, and the animal was injected intramuscularly with 10,000 units penicillin.

For measurement of the drug-induced circling behavior. rats were placed in individual testing cages $(35 \times 25 \times 18 \mathrm{~cm})$ and left undisturbed for adaptation to the cage for $1 \mathrm{hr}$. Circling behavior was directly observed for $2 \mathrm{hr}$ and a $360^{\circ}$ turn was considered as one circling count. The number of complete turns and the direction of circling were recorded for $5 \mathrm{~min}$ at 15,30 . 60,90 and $120 \mathrm{~min}$ following the administration of drugs. Apomorphine $\mathrm{HCl}$ and methamphetamine $\mathrm{HCl}$ were administered intraperitoneally as a salt. Circling responses to methamphetamine (Dainippon Phar- maceuticals) $(2.0 \mathrm{mg} / \mathrm{kg})$ or apomorphine (Sigma) $(1.0 \mathrm{mg} / \mathrm{kg})$ were determined 8 days following the surgical operations. One day after surgery, animals were pretreated with 2 daily subcutaneous injections of saline (1.0 $\mathrm{ml} / \mathrm{kg}$ ) or $1.0 \mathrm{mg} / \mathrm{kg}$ haloperidol (Dainippon Pharmaceuticals) for 7 days. At the end of the behavioral experiments, the animals were sacrificed under deep pentobarbital sodium anesthesia and perfused with 10\% formalin. Frozen $50 \mathrm{~km}$ thick sections of the whole brain were cut using a freezing microtome. The location of each lesion site was verified. Only rats in which the lesion target was comfirmed histologically were included in the analysis of the behavioral data. Student's $t$-test was used for statistical evaluation of the data. Less than 0.05 level of probability was accepted as significant.

Consistent with previous report (8). unilateral injection of colchicine $(20 \% \mathrm{~g} /$ animal) into the SNC produced animals that showed a slight occasional bias in their posture toward the injected side and became aggressive 3-8 days after the treatment. As shown in Fig. 1, rats injected with colchicine into the SNC rotated toward the side of

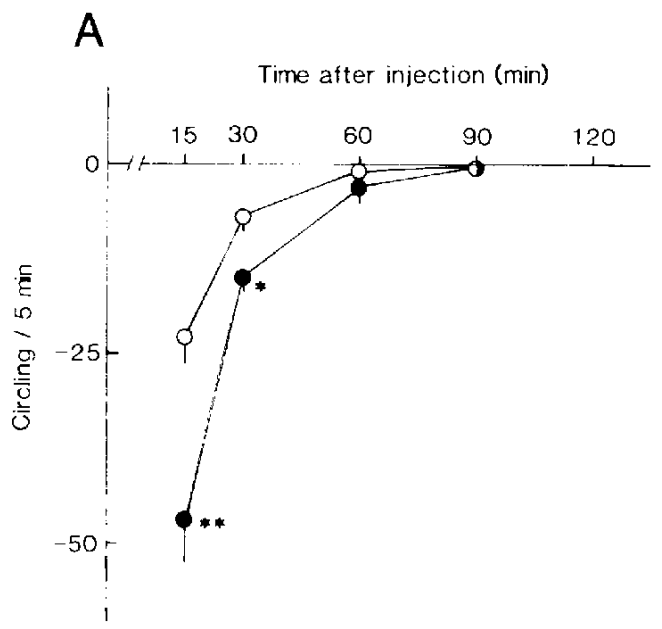

B

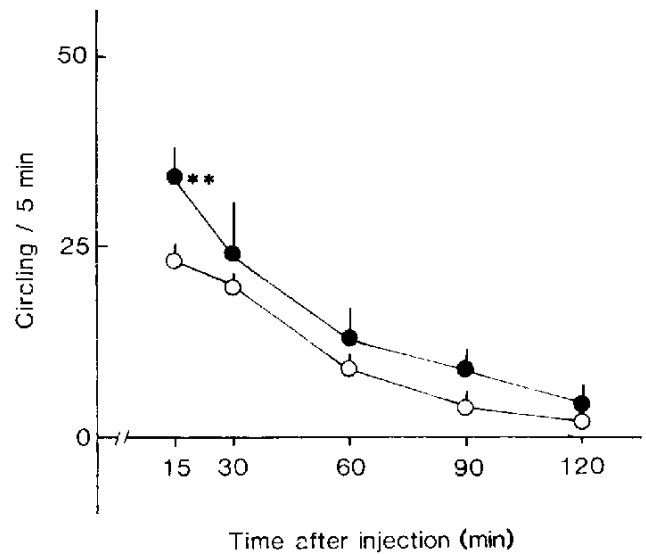

Fig. 1. Circling behavior induced by apomorphine $(A)$ and methamphetamine (B) in rats microinjected with colchicine into the SNC. Drugs were given 8 days following infusion of colchicine. Each symbol, (closed circle. subchronic haloperidol-treated rats: open circle. subchronic saline-treated rats), represents

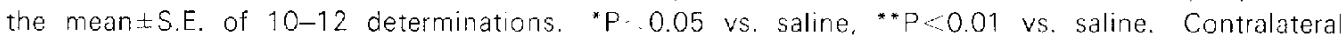
circling is indicated by positive numbers (upward direction), and ipsilateral circling is indicated by negative numbers (downward direction). 
infusion after $1.0 \mathrm{mg} / \mathrm{kg}$ of apomorphine (ipsilateral circling: indicated by negative numbers and a downward direction) and away from the side of infusion after $2.0 \mathrm{mg} /$ $\mathrm{kg}$ of methamphetamine (contralateral circling: indicated by positive numbers and an upward direction). The characteristic response to both drugs was tight, 'nose-to-tail' turning. Both apomorphine and methamphetamineinduced ipsilateral or contralateral circling behaviors were significantly increased by treatment with subchronic haloperidol as shown in Fig. 1 .

In the present experiments, methamphetamine produced contralateral circling behavior in rats injected with colchicine into the SNC. It has been recently reported that postsynaptic dopamine receptors in the striatum ipsilateral to the injection side appear to be supersensitive to the released dopamine, and colchicine might produce changes in postsynaptic dopamine receptors by interrupting the influence of some neurotrophic factor(s): e.g., trophic factor(s) via an inhibitory action of the fast axonal transport system as it is known to do in the peripheral adrenergic nerve fibers (9-11). Chronic haloperidol treatment produced further supersensitivity, indicating that development of supersensitivity following colchicine and subchronic haloperidol involve different regulatory processes; i.e., these treatment can lead to independent processes of postsynaptic supersensitivity. Of particular interest in this connection is the observation that in animals with bilateral injections of 6 hydroxydopamine into the nucleus accumbens and chronic haloperidol administration, there is a greater increase in the density of ${ }^{3} \mathrm{H}$-spiperone-binding sites than there is with either treatment alone, and the affinity constant is not altered $(19,20)$.

On the other hand, apomorphine produced an ipsilateral circling behavior on day 8 in rats injected with colchicine into the SNC. Apomorphine produces contralateral circling in unilaterally 6-hydroxydopamine-denervated rats (21, 22). Herrera-Marschitz and Ungerstedt (27) demonstrated that the contralateral apomorphine rotation is converted into ipsilateral turning following kainic acid lesion of the substantia nigra, although con- tralateral circling is maintained. They suggested that this conversion of apomorphineinduced contralateral rotation into ipsilateral circling is mainly dependent upon striatonigral pathways. It is conceivable, therefore, that apomorphine-induced ipsilateral circling in colchicine-treated rats may be responsible for striatonigral pathways on the intact side. Chronic treatment with haloperidol enhanced apomorphine-induced ipsilateral circling. indicating that chronic haloperidol might produce the enhancement of striatonigra pathways as suggested by Gale (28) and Huffman and Tick (29). They reported that the chronic administration of hatoperidol resulted in a significant increase in binding of GABA to receptors in the substantia nigra This idea is one of various possibilities With respect to the detailed mechanism concerning the enhancement of apomorphine-induced ipsilateral circling by subchronic haloperidol in colchicine-treated rats. further investigations are required.

\section{References}

1 Albuquerque, K., Warnick, J.F., Tasse, J.R. and Sansone, F.M.: Effects of vinblastine and colchicine on neuronal regulation of the fast and slow skeletal muscle of the rat. Exp. Neurol. 37, $607-634$ (1972)

2 Felnandez, H.L. and Ramirez, B.U.: Muscle fibrillation induced by blockade of axoplasmic transport in motor nerves. Brain Res. 79, 385 395 (1.974)

3 Hoffman, W.W. and Thesleff, S.: Studies on the trophic influence of evidence on skeletal muscle. Eur. J. Pharmacol. 20, 256-260 (1972)

4 Schalow, G. and Schmidt, H.: Effect of length and temperature on the induction of action potentials in denervated slow muscle fibers of the frog. Pflügers Arch. 372, 17-22 (1977)

5 Goto, K.: Electrophysiological analysis of colchicine-induced supersensitivity in the rat vas deferens. J. Physiol. (Lond.) 308, 465-477 (1980)

6 Goto, K., Masaki, T., Saito, A. and Kasuya, Y.: Deneration-like supersensitivity in the rat vas deferens induced by local application of colchicine to the hyoogastric plexus. J. Pharmacol. Exp. Ther. 209, 376-381 (1979)

7 Saito, A., Kasuya, Y. and Goto, K.: The role of morphological and functional changes in adrenergic nerves for the development of colchicineinduced supersensitivity in the rat vas deferens. 
J. Pharmacol. Exp. Ther. 217, 516--523 (1981)

8 Kamata, K., Kameyama, T., Okuyama, S., Hashimoto, S. and Aihara, H.: Denervation-like postsynaptic supersensitivity to dopamine agonists induced by microinjection of colchicine into the substantia nigra pars compacta. Brain Res. 367, 1-7 (1986)

9 Banks, P., Mayor, D., Mitchell, M. and Tomlison, D.: Studies on the translocation of noradrenalinecontaining vesicles in postganglionic sympathetic neurons in vitro. Inhibition of movement by colchicine and vinblastine and evidence for the involvement of axonal microtubules. J. Physial. (Lond.) 216, 625-639 (1971)

10 Banks, P. and Till, R.: A correlation between the effects of anti-mitotic drugs on microtubule assembly in vitro and the inhibition of axonal transport in noradrenergic neurons. J. Physiol. (Lond.) 252, 283-294 (1975)

11 Dahlstrom, A.: Axoplasmic transport (with particular respect to noradrenergic neurons). Philos. Trans. R. Soc. Lond. [Biol.] B261, 325358 (1971)

12 Iversen, S.D. and Creese, I.: Behavioral correlates of dopaminergic supersensitivity. Adv. Neurol. 9, 81-92 (1975)

13 Muller, P. and Seeman, P.: Dopaminergic supersensitivity after neuroleptics: Time-course and specificity. Psychopharmacology (Berlin) 60, 1-11 (1978)

14 Schwartz, J.C., Costentin, J., Martres, M.P., Protais, P. and Baudy, M.: Modulation of receptor mechanism in the CNS: Hyperactivity to catecholamines. Neuropharmacology 17, 665685 (1978)

15 Burt, D.R., Creese, I. and Snyder, S.H.: Antischzophrenic drugs: Chronic treatment elevates dopamine receptor binding in brain. Science 196, 326-328 (1976)

16 Von Voigtlander, P.F., Losey, E.G. and Triezenberg, H.J.: Increased sensitivity to dopaminergic agents after chronic neuroleptics treatment. J. Pharmacol. Exp. Ther. 193, 88-94 (1975)

17 Smith, R.C. and Davis, J.M.: Behavioral evidence for supersensitivity after chronic administration of haloperidol, clozapine, and thioridazine. Life Sci. 19, 725-732 (1976)

18 Christensen, A.V. and Moller-Nilsen, I.: Dopaminergic supersensitivity: Influence of dopamine agonists, cholinergics, anticholinergics and drugs used for the treatment of tardive dyskinesia.
Psychopharmacology (Berlin) 62, 111-116 (1979)

19 Staunton, D.A., Magistretti, P.J., Koob, G.F., Shoemaker, W.J. and Bloom, F.E.: Dopaminergic supersensitivity induced by denervation and chronic receptor blockade is additive. Nature 299 , $72-74(1982)$

20 Reches, A., Wagner, R.H., Jackson, V., Yablonskaya-Alter, E. and Fahn, S.: Dopamine receptors in the denervated striatum: Further supersensitivity by chronic haloperidol treatment. Brain Res. 275, 183-185 (1983)

21 Ungerstedt, $\mathrm{U}$ : Striatal dopamine release after amphetamine on nerve degeneration revealed by rotational behaviour. Acta Physiol. Scand. Supp. 367, 49-68 (1971)

22 Ungerstedt, U.: Postsynaptic supersensitivity after 6-hydroxydopamine-induced degeneration of the nigrostriatal dopamine system. Acta Physio!. Scand. Supp. 367, 69-93 (1971)

23 Kamata, K., Kamata, M., Ino, H. and Kameyama, T.: Changes in catecholamine-sensitive $\mathrm{Na}^{+}, \mathrm{K}^{+}-$ ATPase activity in the rat striatum microsomes following electrolytic or 6-hydroxydopamineinduced lesions of dopaminergic neurons. Japan. J. Pharmacol. 30, 401-404 (1980)

24 Kamata, K., Kameyama, T., Okuyama, S., Hashimoto, S. and Aihara, H.: Contralateral circling behavior induced by intranigral microinjections of taurine and GABA in rats. Brain Res. 343, 275282 (1985)

25 Kamata, K., Sugimoto, A. and Kameyama, T.: Effect of chronic haloperidol on dopamine release following microinjection of GABA into the substantia nigra zona reticulata in the rat. Brain Res. 380, 1-6 (1986)

26 König. J.F.R. and Klippel, R.A.: The Rat Brain: A Stereotaxic Atlas of the Forebrain and Lower Parts of the Brain stem. Williams and Wilkins, Baltimore (1963)

27 Herrera-Marschitz, M. and Ungerstedt, U: Evidence that striatal efferents relate to different dopamine receptors. Brain Res. 323, 269-278 (1984)

28 Gale, K.: Chronic blockade of dopamine receptors by antipsychotic drugs enhances GABA binding in substantia nigra. Nature 283, 569-570 (1980)

29 Huffman, R.D. and Tick, M.K.: The effects of chronic haloperidol administration on GABA receptor binding. Pharmacol. Biochem. Behav. 19, 199-204 (1983) 